Ensino, Saúde e Ambiente - V5 (2), pp. $114-125$, ago. 2012

\title{
CIÊNCIA ITINERANTE: PROJETO DE EXTENSÃO AUXILIANDO A PRÁTICA DE ENSINO DE BIOLOGIA
}

\section{ITINERANT SCIENCE: EXTENSION PROJECT HELPING THE PRACTICE OF TEACHING BIOLOGY}

\author{
${ }^{1}$ João Rodrigues Miguel; ${ }^{2}$ Carlos Eduardo Silva Jascone; ${ }^{3}$ Wellington R. de Matos; ${ }^{3}$ Maria \\ Luiza Ribeiro; ${ }^{3}$ Ricardo O. Vasques; ${ }^{3}$ Leandro Duarte da Cruz e ${ }^{4}$ Carlos H. de Freitas Burity. \\ ${ }^{1}$ Docente do programa de Pós-graduação em Ensino de Ciências e do Curso de Ciências \\ Biológicas da UNIGRANRIO e da secretaria de educação do Estado do Rio de Janeiro \\ (SEE) jmiguel@unigranrio.com.br \\ ${ }^{2}$ Docente da SEE e da SME do Rio de Janeiro, eduardojascone@yahoo.com.br \\ ${ }^{3}$ Docente de graduação em Biologia da UNIGRANRIO \\ ${ }^{4}$ Coordenador do Programa de Pós-graduação em Ensino de Ciências e do Curso de Ciências \\ Biológicas da UNIGRANRIO, cburity@unigranrio.com.br
}

\section{RESUMO}

A idéia é estreitar a relação entre o saber científico e a sociedade. Trabalhando no Estado do Rio de Janeiro com subprojetos, tem como meta a organização de um acervo com espécies animais e vegetais, mapeamento de trilhas em Unidades de Conservação (UC) e a elaboração de protocolos de estudo sobre ecossistema. Os resultados com a denominação de "Ciência Itinerante" são apresentados por discentes treinados sob a forma de palestras ou em stands em eventos, ou geram trabalhos para divulgação. Percebem-se nestas apresentações os estímulos para as novas pesquisas. Com esse programa a - UNIVERSIDADE VAI ALÉM DA SALA DE AULA - quando atende a alguns anseios da sociedade. Com uma atuação participativa e criativa e utilizando-se de um acervo atrativo, procura apresentar as atividades que o profissional da biologia pode desenvolver na prática estimulando a reflexão.

Palavras chaves: ensino, biologia, biodiversidade.

\begin{abstract}
The idea is to strengthen the relationship between scientific knowledge and society. Working in the State of Rio de Janeiro with subprojects, aims to organize a collection of animal and plant species, mapping trails in Conservation Units (UC) and the development of study protocols on the ecosystem. The results with the name "Traveling Science" is presented by students trained in the form of lectures or booths at events, or generate work for publication. It can be seen in presentations at events stimuli for further research. With this program - UNIVERSITY GOES BEYOND THE CLASSROOM - when it meets some expectations of society. With a creative and participatory activities and using a collection of attractive, seeks to present the activities that the professional can develop biology encouraging reflection on practice.
\end{abstract}

Keywords: education, biology, biodiversity.

INTRODUÇÃO 
O conhecimento popular é intuitivo, inexato e imediatista, desprovido de um embasamento cientifico e com fortes inclinações para o descrédito, embora importante, pois é ponto de partida (hipótese). Esse conhecimento carece de estudo, análise e comprovação científica; ele surge das experiências empíricas de cada um, das crenças do senso comum (conhecimento popular) não foram submetidos a testes sistemáticos realizados à luz de dados obtidos para determinar se são fidedignos, qual o seu alcance e validade (NAGEL, 2008). O Conhecimento Científico vai além das situações e impressões, ele permite perceber o fenômeno para então compreender as causas e leis que o regem. É aquele conhecimento que busca explicar de forma sistematizada e racional, portanto lógica, a verdade dos fatos. Sua marca é a comprovação (Campbell, N. A.; Reece, J. B. 2010.).

Comprometidos com o saber universitário propõem-se levar ao público informações comprovadas e que redundam em conhecimento científico, utilizando-se de uma linguagem apropriada que permita uma redução da distância entre a universidade e a população, apoiando o ensino, a pesquisa e a extensão. O Ministério da Educação e Cultura MEC preconiza a integração entre a Educação de Jovens e Adultos (EJA) e a vida cidadã, de modo que cada componente curricular contribua com uma melhor orientação para o trabalho e com a implicação dos significados das experiências de vida dos alunos. Eles devem ter acesso ao conhecimento que poderá promover e ampliar suas interpretações sob os aspectos individuais e coletivos que condiciona saúde, reprodução humana e a transformação dos ecossistemas no planeta melhorando a condição humana. Questões como essas pautam a formulação desta proposta para o currículo de Ciências Naturais (MEC/DOT 2007). Neste sentido buscam-se meios de se viabilizar de uma maneira criativa a transferência destes conhecimentos a um público leigo.

A justificativa é levar ao publico esclarecimentos às suas inquietações e dúvidas baseadas no compromisso universitário. O profissional da biologia busca respostas aos anseios e interesses individuais e comunitários além de informar, onde o interessado pode resolver problemas que afetam diretamente seu modo de vida, esclarecendo sobre órgãos e instituições que possam ajudá-lo (www.crbio01.gov.br 2012). Assume também um papel de atualização junto a outros profissionais ou ainda, auxilia o estudante, dos diferentes níveis de escolaridade, sobre a escolha de sua formação acadêmica, para tanto idealiza seminários, palestras, encontros onde esclarece sobre a praxe desse profissional da área da saúde.

\section{MATERIAIS E MÉTODOS}

A partir de uma primeira apresentação do projeto determinou-se o ponto de partida para tornar-se itinerante, foram feitos encontros entre a equipe de pesquisadores e os 
discentes envolvidos. Durante esses encontros foi solicitado aos alunos que escrevessem, num portfólio, as experiências e impressões, que cada um teve durante as aulas de capacitação e a apresentação em questão. Os dados coletados forneceram informações sobre como o público reagia, que assunto chamava mais atenção, quais as dúvidas mais comuns. Estes dados foram importantes para observar a necessidade da continuação destas mostras de ciência e para deliberar sobre novas apresentações.

Atualmente o Projeto Ciência Itinerante que obteve financiamento da FAPERJ (E26/111.470/2010) é desenvolvido através dos Subprojetos:

\section{Subprojeto 1 - Herbário Didático da Unigranrio}

A partir da aprovação do Subprojeto, sob a supervisão da coordenação e do bolsista, os envolvidos, durante os 24 meses que corresponde ao período de realização do estudo se comprometeram a mensalmente a participar de excursões, em trilhas delimitadas em Unidades de Conservação, com o objetivo de coletar táxons férteis para identificação. No material coletado foram aplicadas as técnicas de herborização para montagem das coleções (Martins da Silva 2002). Cada espécime originou, sempre que possível, três amostras: uma incorporada ao acervo do herbário didático da UNIGRANRIO; as outras duas, quando necessário foram realizadas permutas com outras instituições de pesquisa (IPJBRJ, Museu Nacional entre outras).

Com o auxílio da bibliografia especializada, supervisão de pesquisadores em taxonomia e a consulta a herbários do Estado do Rio de Janeiro; os estagiários identificaram as espécies existentes segundo o APG II e III (Judd et al 2003; Souza, V.C. \& Lorenzi, H. 2005.). Coleta de material em fruto e ou sementes serão utilizadas para montagem de uma carpoteca (Peixoto, A.L. , 2003). Além disso, será confeccionado um relatório constando de listagem das espécies e de suas características com a definição dos principais tipos de vegetação. Com base nesses dados o trabalho será submetido a comissões, para que seus resultados possam ser divulgados em congressos, jornadas ou simpósios dessa área do conhecimento científico.

\section{Subprojeto 2 - Bionatrilha}

O planejamento das ações deste subprojeto que é desenvolvido em parques e Unidade de Conservação (UC) do Estado do Rio de Janeiro se dá por meio de escolhas das áreas, adotando critérios como: segurança, localização e facilidade de transporte, atrativos naturais e o estado de conservação. Essas informações são recolhidas nos portais das unidades federais 
o IBAMA (http://www. ibama.gov.br), para estaduais o IEF e INEA (http://www.ief.rj.gov.br) e para as municipais a RIOTUR (http://www.riotur.rj.gov). As atividades seguem uma ordem crescente de dificuldade, permitindo aos participantes aprimorar seus conhecimentos sobre seus limites e condicionamentos físicos. Após a escolha das áreas foi fechado e divulgado na comunidade acadêmica um calendário dos eventos.

Para as ações conta-se com os três professores responsáveis que orientam o grupo junto com 2 monitores, utilizando rádios tipo - Talk about. As inscrições são realizadas no site da Unigranrio. O controle da freqüência se dá através de rubrica e ou assinatura em uma lista de inscritos.

A justificativa para este Subprojeto se dá por que ele atende a necessidade de complementar a formação teórica dos acadêmicos. As atividades práticas são fortemente incentivadas, atendendo as exigências do Projeto Pedagógico dos cursos envolvidos e pelo Conselho Federal de Biologia. Essas ações possibilitam que os egressos destes cursos tenham Know How para quando atuando no mercado profissional, possam desenvolver suas ações de acordo com o contexto de trabalho de cada um. A simples conscientização promovida por agentes multiplicadores podem ajudar a garantir a sustentabilidade destes remanescentes naturais.

\section{Subprojeto 3 - Biólogos em Ação}

Este subprojeto contribui para uma formação profissional consciente, com a promoção de uma melhoria ambiental dentro de uma UC selecionada e assim torna-se um instrumento eficiente de ação educativa no que diz respeito a responsabilidade social. $\mathrm{O}$ Subprojeto permite desenvolver o conhecimento sobre o Meio Ambiente e suas transformações, compreendendo seus fenômenos e usando com critério seus recursos, valorizando a área ambiental.

Objetiva passar conhecimento prático e teórico na área de Educação Ambiental e da pesquisa científica; desenvolvendo o interesse de acadêmicos de Ciências Biológicas e voluntários, enfocando e direcionando atividades para a temática de Conservação dos recursos naturais e dos ecossistemas encontrados no PARNAMTA; dar oportunidade de desempenhar habilidades e atitudes em campo, frente ao conteúdo que recebeu em aulas teóricas e práticas; estimular o desenvolvimento de uma visão crítica e, quando possível, torná-lo responsável por atividades, para que chegue a conclusões práticas, apresentando sugestões positivas; identificar e caracterizar as causas e conseqüências de uma ação 
antrópica sobre o ecossistema da UC visitada, reconhecendo os problemas gerados sobre o ambiente da própria sociedade do entorno.

A criação de uma conscientização ambiental como instrumento de Gestão que tem por base um espaço de participação e mobilização social que dá subsídios para a formação da cidadania; identificar, levantar e analisar dados quantitativos referentes aos agentes transformadores do espaço, detectando pontos críticos para o ecossistema; sensibilizar os visitantes em relação ao objeto temático, a partir da abordagem sobre a exploração indevida de recursos naturais, a deposição de lixo, que levam ao rompimento do equilíbrio ecológico, aguçando a preservação da fauna, flora e recursos hídricos, que são fundamentais para manter o ecossistema local assegurando a vida como um todo (Forattini, O. P. 2004).

\section{RESULTADOS}

\section{Caracterização das áreas}

O Ciência Itinerante foi apresentado em eventos realizados pela UNIGRANRIO, como jornadas científicas ou em datas comemorativas, em seus diferentes campi ou em comunidades onde a Universidade atua. "Ponto de referência" a universidade é procurada por grupos que realizam ações sociais promovidas em Igrejas, associações de moradores, Lions Club, em Secretarias de Educação Municipais e na Estadual. Além disto, levamos o programa de extensão para escolas de ensino fundamental e médio, públicas e particulares do Estado do Rio de Janeiro (Miguel \& Oliveira 2007).

O Herbário Didático da Unigranrio e o Biólogos em Ação foram desenvolvidos na área do Parque Natural Municipal da Taquara, em Duque de Caxias - (PARNAMTA). Área decretada Unidade do INCRA em 1992 possui cerca 20.2 hectares, doada à PMDC em junho de 2006 (Jascone, C.E.S \& Miguel, J.R, 2007). Possui parceria com a UNIGRANRIO, que dá suporte através dos seus profissionais da Área Ambiental e com a ajuda dos Estagiários que são encaminhados para a (UC).

O Bionatrilha levou os graduandos do curso de Ciências Biológicas da UNIGRANRIO para as seguintes trilhas no Estado do Rio de Janeiro: Pedra do Conde, Pico da Tijuca na Floresta da Tijuca, Praias Selvagens, em Guaratiba, Parque Penhasco, Dois Irmãos e Morro da Urca, no Centro do Município do Rio de Janeiro; Itacoatiara, em Niterói; trilha no Parque Nacional da Serra dos Órgãos, em Teresópolis e no PARNANTA

\section{Objetivos e formas de atuação}


Os organizadores de cada subprojeto, citados na metodologia selecionaram alunos do curso de Ciências Biológicas para que seus estágios atendessem os objetivos e as justificativas assim caracterizadas:

O Ciência Itinerante visa levar informação científica à população em geral e ao público estudantil nos segmentos do ensino fundamental e médio, para estes, além da mostra de ciência são ministradas palestras voltadas a assuntos de interesse pertinentes às Ciências Biológicas (Miguel \& Oliveira 2007) . Neste sentido promove atualização das pessoas interessadas nesta área do conhecimento científico e ainda desperta nos estudantes interesse e possível opção por este ramo de atuação profissional.

O Herbário Didático da UNIGRANRIO está fundamentado nos seguintes questionamentos: Que vegetais podemos utilizar no reflorestamento de uma área? Que espécies vegetais são nativas de uma determinada região? Como reconhecer o Bioma característico de uma área geográfica? As respostas embasadas para estes e outros questionamentos você tem que documentar com a sigla de um herbário. Segundo GuedesBruni et al. (2002) e Peixoto, A.L. , (2003). "herbário é uma coleção de espécimes vegetais identificados e catalogados". Com o crescente avanço demográfico, com muita frequência, os profissionais que necessitam de espécies vegetais para demonstrar aos seus alunos, sentem dificuldades em consegui-los. Este projeto tem por objetivo a elaboração de uma coleção de plantas desidratadas para tentar minimizar esse problema.

Bionatrilha

Antes da colonização européia a Floresta Atlântica cobria cerca 15\% do território brasileiro, uma área superior a 1,3 milhões de $\mathrm{km} 2$, perpassando na divisão política brasileira por 17 estados. Após passar por diversos ciclos de exploração econômica e ocupação do território essa área foi reduzida a menos de $8 \%$, ou seja, cerca de $100 \mathrm{mil} \mathrm{km2}$. No estado do Rio de Janeiro estima-se que ela recobria quase que integralmente seus limites, que giravam em torno de $44.541 \mathrm{~km} 2$, os quais se encontram, atualmente, reduzidos a $21,26 \%$ da cobertura original. (SOS Mata Atlântica, 2007).

O Domínio da Mata Atlântica abriga $61 \%$ da população brasileira e concentra as maiores cidades e os grandes pólos industriais do Brasil e, mesmo após tantos anos de devastação, ainda é detentora do recorde mundial em diversidade para plantas lenhosas exemplificadas pelas 458 espécies inventariadas em 1 ha. de floresta ao Sul da Bahia (BRASIL, 2002). Isso demonstra a necessidade de mais estudos florísticos e fitossociológicos 
em remanescentes de Mata Atlântica, independente de sua localização ou estado de conservação.

A necessidade de se estudar as florestas urbanas pode ser entendida não somente no tempo presente, mas também nas perspectivas para o futuro. Segundo o World Resource Institute (2001) a urbanização é um fenômeno mundial. Estima-se que em 2025, entre 75 e $80 \%$ da população sul americana esteja vivendo em cidades. No Brasil mais de $75 \%$ da população é urbana segundo o IBGE (www.ibge.gov.br), com tendência a aumentar. Mesmo residindo próximo a grandes áreas de Florestas Tropicais Urbanas, existem acadêmicos do Curso de Ciências Biológicas não tiveram a oportunidade de vivenciar a importância destas áreas. Hunter (2001) estudou o que, no contexto europeu, que em todas as florestas urbanas algumas atividades são comuns, entre elas as caminhadas e atividades de fim de semana. $\mathrm{O}$ autor conclui que as florestas atendem a uma grande demanda da população por espaços agradáveis de convivência e que elas contribuem para redução do estresse e da violência. Vale lembrar que as principais áreas chamadas de floresta urbana pelos europeus são semelhantes aos Parques Brasileiros. No Brasil estudos deste tipo ainda são raros.

Nesse sentido as ações com os acadêmicos do Curso de Ciências Biológicas e Tecnólogo em Gestão Ambiental visam não apenas conscientização, mas também fazer com que estes sirvam de agentes multiplicadores, junto aos familiares e amigos. Estes também por muitas vezes são convidados a participar das ações. Os alunos tem chance de praticar os conceitos aprendidos e ter contato prático com a natureza, atuando como agentes multiplicadores junto aos seus familiares, amigos e alunos sobre a importância da preservação das áreas naturais urbanas.

A justificativa é que se atende a necessidade de complementar a formação teórica incentivando as atividades práticas. Atividades que estão implícitas no Projeto Pedagógico dos cursos envolvidos. Essas ações possibilitam que os egressos destes cursos tenham Know How para que quando, atuando no mercado profissional possam desenvolver suas próprias ações, de acordo como o contexto de trabalho de cada um. A simples conscientização promovida por estes "agentes multiplicadores" pode ajudar a garantir a sustentabilidade destes remanescentes naturais.

Elaborado em 2006 com o objetivo de proporcionar atividades que contribuem para a formação profissional dos seus participantes e, preocupado com a melhoria ambiental dentro do PARNAMTA, O Subprojeto Biólogos em Ação torna-se um instrumento eficiente de ação educativa no que diz respeito a responsabilidades social, também é fundamental para desenvolver o conhecimento sobre o Meio Ambiente e suas transformações, compreendendo 
seus fenômenos e usando com sabedoria seus recursos, valorizando o conhecimento científico na área ambiental. Este Projeto auxilia nas transformações participativas e individuais dos integrantes do corpo de estagiários, voluntários e comunidade local da Taquara - Duque de Caxias - RJ, onde fica localizada a (UC) que disponibiliza seu espaço físico para a realização do nosso trabalho.

\section{CONCLUSÕES}

O Subprojeto 1 Ciência Itinerante: teve seu marco inicial no ano de 2006 estando em plena atividade e desenvolvimento desde então, tendo atingido em 2011, um público superior a 10.000 ouvintes, com média de idade variando entre 10 e 60 anos, com destaque para o público infantil e jovem que, onde o Subprojeto é apresentado participa ininterruptamente de suas atividades. Para este público sempre ávido e sedento em aprender, disponibiliza a informação e colabora com a democratização do conhecimento, motivado pelas peças expostas às quais têm a primazia nesta transferência de conhecimentos aguçando o interesse e atenção do público ao qual, os acadêmicos têm a ensinar, abrindo definitivamente um rico canal de comunicação entre a Universidade e as comunidades e escolas visitadas.

Nas comunidades visitadas observou-se o interesse do público pelas informações recebidas tendo em vista da carência por informações baseadas em dados científicos e fidedignos, quando levamos conteúdo de qualidade e relevante a vida da comunidade, percebemos o quanto este tipo de trabalho traz em benefícios as pessoas e comunidades como um todo.

Em 2011 deu-se inicio a um novo ciclo do projeto pois, a equipe que até então se responsabilizava pelo trabalho concluiu seu ciclo de estudo sendo automaticamente desligada da Instituição e do projeto. Fato consumado começou-se um novo trabalho de conscientização de uma nova turma sendo lançado um edital de monitoria onde 10 alunos se inscreveram. Montou-se então um curso de capacitação para estes alunos que, ao final do período fez uma apresentação do projeto em um Colégio da Zona Oeste do Rio de Janeiro, que foi muito elogiada.

O subprojeto 2 Herbário didático que teve seu inicio com a incorporação de 720 exsicatas onde, 370 são samambaias e 350 angiospermas. Estes espécimes foram formados como resultado de um Projeto de IC "Levantamento Florístico da Reserva Estadual do Paraíso no Estado do Rio de Janeiro" desenvolvido com financiamento da FAPERJ. A este foram incorporados os materiais oriundos das coletas provenientes das coletas regulares 
realizadas a partir de novembro de 2010, data da aprovação desse novo projeto até a presente data.

As coletas foram realizadas uma a cada mês, perfazendo um total de 950 exsicatas. Os estagiários e alunos de IC, além das coletas desenvolveram todo o processo de herborização e identificação do material botânico. Desenvolveram seus Trabalhos de Conclusão de Curso e foram treinados para as defesas de seus projetos. As coletas agora são em áreas do parque da Taquara onde não existe uma trilha estabelecida e, não raro se cria o caminho para que se consiga um deslocamento para observação e seleção do material. Com a divulgação do projeto feita entre os alunos, aponta-se que em 2011 o projeto acolheu um aluno de Iniciação Cientifica com bolsa da FUNADESP; seis alunos (Três duplas ) cumpriram tarefas de estágio e desenvolveram seus Trabalhos de Conclusão de curso. Sete alunos (3três duplas e um) cumpriram as tarefas de Estágio voluntário e (duas duplas) realizaram o TCC de Bacharelado.

As atividades do subprojeto Bionatrilha foram realizadas em trilhas da Cidade do Rio de Janeiro, sempre em Unidades de Conservação. Em meio aos belos cenários os alunos tiveram contato com diversos elementos da fauna e flora. Não raro aconteceu a participação de alunos de outros cursos e parentes dos alunos, o que contribuiu para a divulgação das Ciências Biológicas, bem com para a importância da preservação ambiental. A evolução do projeto nesses anos deu origem a novas atividades como oficinas, cursos e até gincanas. Dentre as áreas temáticas abordadas estão à utilização de GPS, técnicas de campo e a preservação da biodiversidade. O número de alunos participantes do projeto passou de 18 , quando este começou no segundo semestre de 2008, para 216 em 2011. Neste ano $68 \%$ dos participantes foram a apenas um evento, $20 \%$ a dois eventos e $12 \%$ a três ou mais.

O subprojeto gerou recurso através da cobrança de inscrições, que foi utilizado na aquisição de livros que foram distribuídos as participantes. As unidades de conservação visitadas, vide relação na metodologia. Este projeto conta com a participação direta de três docentes de Curso de Ciências Biológicas, além de três monitores para as atividades de campo.

O Projeto Biólogos em Ação oferece possibilidades para desenvolvermos dinâmicas que elevam a responsabilidade com a conservação, sustentabilidade e cuidados com os ecossistemas. Avalia-se o Projeto como algo inovador, capaz de estimular mudanças positivas no comportamento na comunidade freqüentadora do PARNAMTA e no desenvolvimento profissional de acadêmicos estagiários de Ciências Biológicas. 
O grupo atendido demonstrou grande interesse pelos temas, tornando-se responsáveis em gerar recursos para promoção de uma mudança de atitude da comunidade local e dos visitantes, além de realizar mudanças significativas de caráter sócio-Ambiental.

Esse publico alvo é constituído de alunos da rede pública e particular de ensino; visitantes da Unidade de Conservação do Parque Natural Municipal da Taquara, da sua atuação destacam-se como resultados o reflorestamento no entorno da Sede, onde está sendo feita a substituição de espécies exóticas por espécies nativas; capacitação de Professores da Rede Municipal; pesquisas em diversas áreas como Ecologia, Botânica e Zoologia;

O Mico-Leão-Dourado (Leontopithecus rosalia), endêmico da região, outrora sem registro de ocorrência, considerado espécie em extinção, foi avistado dentro do PNMT em 2007, rendendo publicação científica a respeito do fato, com a equipe de Biólogos do PNMT e da UNIGRANRIO, sob Coordenação do Prof. Dr. Carlos Henrique de Freitas Burity.

Foi formatada uma FOTOTECA onde se armazena e cataloga material das áreas de Botânica, Zoologia, Geografia, Geologia e Educação Ambiental, que servirão como material de apoio no ensino, pesquisa e desenvolvimento interno. Usada na sistematização da documentação fotográfica, efetuando, também serviço de aquisição, seleção, análise e recuperação e disseminação de informações, intercâmbio com entidades congêneres e pesquisas seletivas para subsidiar as atividades técnicas do Parque e atendimento ao Público em geral. Constituída ao longo do tempo, com a aquisição, doação de imagens e fotografias pelos funcionários do PNMT, Universidades parceiras, Professores, Pesquisadores, Estagiários e Voluntários.

O acervo deverá se destacar por sua importância, uma vez que dentre as imagens diversas, será destacada informações de grande valor, implicando na aplicação de procedimentos de conservação e segurança. Nos registros constarão informações sobre o local fotografado, data e quem realizou o registro fotográfico, assim como seu vínculo com o PNMT. Todo acervo se encontra à disposição para consulta e pesquisa em várias áreas e apresentações, promovendo, realizando e divulgando o ensino e as pesquisas técnico cientificas sobre a biodiversidade do Parque, visando o conhecimento e a conservação dos ecossistemas.

Os Estagiários vinculados a UC doarão cópias desses registros fotográficos para o acervo, que deverá ser arquivado com todos os dados pertinentes à pesquisa em fichário apropriado. Ao final de cada período, será montado um conjunto de Banners para exposição do trabalho desenvolvido. 


\section{REFERÊNCIAS BIBLIOGRAFICAS}

BRASIL 2002. Biodiversidade Brasileira. Avaliação e identificação de áreas e ações prioritárias para conservação Utilização sustentável e Repartição de Benefícios da Biodiversidade Brasileira. Brasília - DF. Ministério do Meio Ambiente. 5a . ed.

CAMPBELL, N. A.; REECE, J. B. Biologia. 8ª ed. Artmed, 2010.

FORATTINI, O. P. Ecologia, Epidemiologia e Sociedade. 2a ${ }^{a}$ ed. São Paulo: Artes Médicas, 2004 .

GUEDES BRUNI, R. et al. in SYLVESTRE, L.da S. 2002. Manual Metodológico para

Estudos Botânicos da Mata Atlântica. Rio de Janeiro: Editora da Universidade Rural.

HUNTER, I.R. 2001. What do people want from urban forestry? The European experience Urban Ecosystems, 5: 277-284

JASCONE, C.E.S \& MIGUEL, J.R. 2007. PTERIDOFLORA DA ESTAÇÃO ESTADUAL DO PARAÍSO RIO DE JANEIRO, BRASIL. Saúde \& Ambiente em revista, Duque de Caxias, v.2, n.1: 37-46.

JUDD, W.S.; CAMPBELL, C.S.; KELLOGG, E.A.; STEVENS, P.F. \& DONOGHUE, M.J., 2002. Plant Systematics: a phylogenetic approach. 2 ed. Sunderland: Sinauer Associates. LUNETTA, V. N. Atividades práticas no ensino da ciência. Revista Portuguesa de Educação, v.2, n.1, p. 81-90, 1991.

MARTINS da SILVA, R.C.V. Coleta e Identificação de Espécimes Botânicos. Embrapa Documentos 143. Belém. Novembro. 2002

MIGUEL, J.R. \& OLIVEIRA, J.R.A. de 2007. CIÊNCIA ITINERANTE: Ações do Biólogo na comunidade. Informativo do Conselho Regional de Biologia da $2^{\text {a }}$. Região/Rio de Janeiro e Espírito Santo. Rio de Janeiro.

NAGEL, E.. Ciência e senso comum. Disponível em:

http://www.didacticaeditora.pt/arte_de_pensar/leit_sensocomum.html. Acesso: 10/10/2009 SOS MATA ATLÂNTICA. 2007. Atlas dos remanescentes florestais da Mata Atlântica. São Paulo. SP. Fundação SOS Mata Atlântica.

PEIXOTO, A.L. 2003. Coleções Biológicas de Apoio ao Inventário, Uso Sustentável e Conservação da Biodiversidade. Rio de Janeiro: Instituto de Pesquisas Jardim Botânico do Rio de Janeiro. 
SOUZA, V.C. \& LORENZI, H.. 2005. Guia Ilustrado para identificação das famílias de Angiospermas da flora brasileira, baseado em APG II. São Paulo: Instituto Plantarum. WORLD RESOURCE INSTITUTE. 2001 Earthtrends: The enviromental information

portal. World Resource Institute, Washington DC, http://earthtrends.wri.org/ Capturado em: 2 de Abril de 2010.

São Paulo (SP). Secretaria Municipal de Educação. Diretoria de Orientação Técnica. Referencial de expectativas para o desenvolvimento da competência leitora e escritora no ciclo II : caderno de orientação didática de Ciências Naturais / Secretaria Municipal de Educação - São Paulo : SME / DOT, 2007.1

Site do Conselho Regional de Biologia, (www.crbio01.gov.br, acessado em 02/2012). 